\title{
A large-scale screening for the taiga tick, Ixodes persulcatus, and the meadow tick, Dermacentor reticulatus, in southern Scandinavia, 2016
}

\author{
Lene Jung Kjær ${ }^{r^{*}} \mathbb{D}$, Arnulf Soleng ${ }^{2}$, Kristin Skarsfjord Edgar², Heidi Elisabeth H. Lindstedt ${ }^{2}$, \\ Katrine Mørk Paulsen ${ }^{3,4}$, Åshild Kristine Andreassen ${ }^{3}$, Lars Korslund ${ }^{5}$, Vivian Kjelland ${ }^{5,6}$, Audun Slettan ${ }^{5}$, \\ Snorre Stuen7, Petter Kjellander ${ }^{8}$, Madeleine Christensson ${ }^{8}$, Malin Teräväinen ${ }^{8}$, Andreas Baum ${ }^{9}$ \\ Anastasia Isbrand ${ }^{10}$, Laura Mark Jensen ${ }^{1}$, Kirstine Klitgaard ${ }^{10}$ and René Bødker
}

\begin{abstract}
The taiga tick, Ixodes persulcatus, has previously been limited to eastern Europe and northern Asia, but recently its range has expanded to Finland and northern Sweden. The species is of medical importance, as it, along with a string of other pathogens, may carry the Siberian and Far Eastern subtypes of tick-borne encephalitis virus. These subtypes appear to cause more severe disease, with higher fatality rates than the central European subtype. Until recently, the meadow tick, Dermacentor reticulatus, has been absent from Scandinavia, but has now been detected in Denmark, Norway and Sweden. Dermacentor reticulatus carries, along with other pathogens, Babesia canis and Rickettsia raoultii. Babesia canis causes severe and often fatal canine babesiosis, and $R$. raoultii may cause disease in humans. We collected 600 tick nymphs from each of 50 randomly selected sites in Denmark, southern Norway and south-eastern Sweden in August-September 2016. We tested pools of 10 nymphs in a Fluidigm real time PCR chip to screen for $I$. persulcatus and D. reticulatus, as well as tick-borne pathogens. Of all the 30,000 nymphs tested, none were I. persulcatus or D. reticulatus. Our results suggest that I. persulcatus is still limited to the northern parts of Sweden, and have not expanded into southern parts of Scandinavia. According to literature reports and supported by our screening results, D. reticulatus may yet only be an occasional guest in Scandinavia without established populations.
\end{abstract}

Keywords: Taiga tick, Ixodes persulcatus, Siberian and Far Eastern tick-borne encephalitis, meadow tick, Dermacentor reticulatus, southern Scandinavia, range expansion

\section{Letter to the Editor}

Tick-borne diseases pose a risk to both humans and animals [1-3], and there is a concern that the increase in incidence and geographical range reported over the last decades [4-8] may be an effect of climate change impacting vectors and their associated pathogens $[9,10]$. In Europe, and especially Scandinavia, the main vector of disease-causing pathogens in humans, pets and other

\footnotetext{
*Correspondence: lenju@sund.ku.dk

${ }^{1}$ Department of Veterinary and Animal Sciences, Faculty of Health

and Medical Sciences, University of Copenhagen, Frederiksberg, Denmark
}

Full list of author information is available at the end of the article large mammals is the castor bean tick Ixodes ricinus [6, 7]. The closely related taiga tick, Ixodes persulcatus, has previously been limited to eastern Europe and northern Asia [11], but within the last 15 years, the species has expanded its range, both in eastern Europe [12, 13] but also towards western Europe [11, 12, 14]. Ixodes persulcatus was recorded in the western parts of Finland in 2004 [14] and 2008 [15], and in northern Sweden in 2015 [11]. Ixodes persulcatus may carry the Siberian and Far Eastern subtypes of the tick-borne encephalitis virus (TBEV) along with a range of other pathogens [11, 16, 17]. The Siberian and Far Eastern subtypes of TBEV have 
been reported to cause more severe symptoms than the European sub-type [17-19], although there is speculation that this may be due to other factors such as clinical alert and reporting $[17,19]$.

The meadow tick, Dermacentor reticulatus, is endemic to Europe [20], and is currently spreading to new geographical areas [20-22]. Dermacentor reticulatus was previously absent from Scandinavia [20], but has been found on migrating birds in Norway as early as 20032005 [23], and potentially in 2009, as Babesia canis was detected in a dog from the Oslo area that had not travelled abroad, indicating that $D$. reticulatus was present in the area [24]. In Sweden, single D. reticulatus has been identified in 2010 in the region of Skåne, in 2012 on a dog that had been abroad and then again two more times in the region of Skåne in 2017 [25]. In Denmark, D. reticulatus was found on a migrating golden jackal (Canis aureus) in 2017 [21], and again in 2018 on a dog that was returning from a trip to Slovakia with its owner [26]. Dermacentor reticulatus carries several pathogens presently absent in Scandinavia, but the most concerning involve B. canis and Rickettsia raoultii. Babesia canis causes canine babesiosis in dogs with a high risk of death [27]. Rickettsia raoultii poses a zoonotic health concern as it may cause disease in humans [21].

As a part of a large Scandinavian project, we randomly selected 30 sites in each of Denmark, southern Norway and south-eastern Sweden for tick collection in August and September 2016. Selection of the 90 sites was based on a stratification scheme with random sampling described in Kjær et al. [28]. Ticks were only analysed from sites where $\geq 600$ nymphs could be collected, resulting in a total of 50 sites (Fig. 1).

We morphologically examined the 30,000 ticks to ensure that they were all nymphs. We aggregated 30,000 collected nymphs into 60 pools of 10 for each site and used the BioMark real-time PCR system (Fluidigm, San Francisco, California, USA) for high-throughput microfluidic RT-PCR. The method is thoroughly described in Klitgaard et al. [29] and Michelet et al. [8]. Along with 18 different pathogens, we simultaneously screened each pool for presence of $D$. reticulatus, I. persulcatus and $I$. ricinus, as described and validated by Michelet et al. [8]. The Fluidigm chip has been used for surveillance of tickborne pathogens and exotic tick species on both flagged ticks and on ticks removed from imported animals in Denmark since 2014. The chip has previously detected $D$. reticulatus on a migrating golden jackal [21].

We found that of the 30,000 nymphs tested, all pools tested positive for I. ricinus, and none for I. persulcatus or $D$. reticulatus. Using simple probability theory, we calculated a measure of "freedom from I. persulcatus/D. reticulatus", using the binomial theorem:

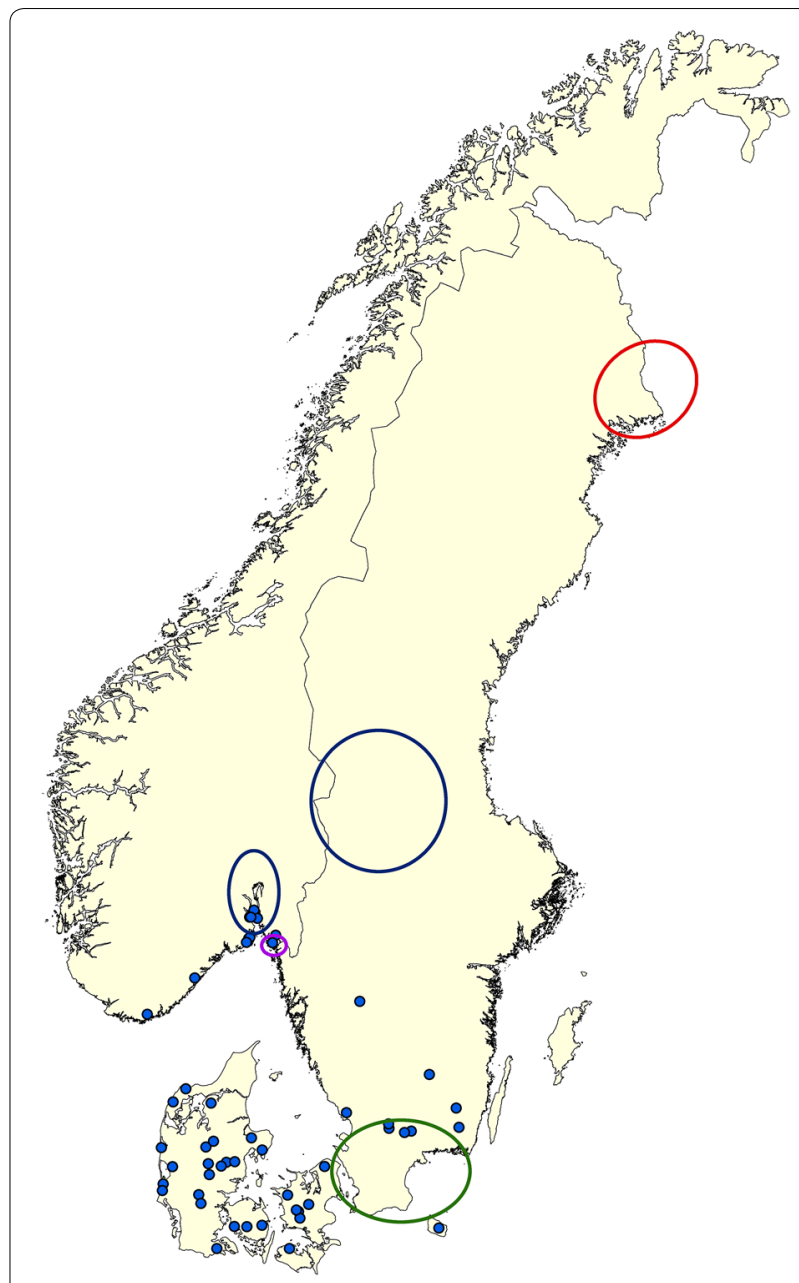

Fig. 1 Map of southern Scandinavia with the 50 sample sites from 2016 depicted (blue dots). At each site, a minimum of 600 tick nymphs were collected. The red ellipse marks the area where I. persulcatus was recorded in 2015 by Jaenson et al. [11]. The blue ellipses are where $D$. reticulatus/B. canis was found associated with dogs $[24,25]$, the magenta ellipse is where $D$. reticulatus was found on birds [23] and the green ellipses is where D. reticulatus has been found in nature [25]

$$
D C=1-(1-\text { prev })^{N}
$$

where $D C$ is the degree of certainty (here 95\%), prev is the proportion of $I$. persulcatus/D. reticulatus, and $N$ is the sample size, here either 600 per site or 30,000 in total.

With this equation, we assume that if $I$. persulcatus/D. reticulatus constitute a proportion higher or equal to prev in all nymphs collected and the PCR is $100 \%$ sensitive in pool sizes of 10 , we can then be $95 \%$ certain that we would detect at least one positive pool. With 600 ticks per site and all pools negative, we are therefore 95\% certain that the proportion of I. persulcatus/D. reticulatus at each given site was lower than $0.5 \%$, given the 
reasonable assumption that the 600 nymphs represent a random sample drawn from a much larger population at the site. Likewise, if the 30.000 nymphs collected in total were a random sample from the entire area, we would be $95 \%$ certain that the proportion of $I$. persulcatus $/ D$. reticulatus would be lower than $0.01 \%$. Therefore, if the two species are individually introduced by e.g. migrating birds to the region, they constitute less than one out of 10,000 flagged nymphs. However, if the two species are not just randomly introduced individuals but instead have become established breeding populations then they are likely to have a spatially clustered distribution in the area. With small clusters the probability of detecting a cluster by screening 50 sites is just $5.8 \%$ at a $95 \%$ certainty level, assuming the proportion of the species in a cluster is high enough to be detected with a sensitivity of $100 \%$ when 600 nymphs are tested per site. Thus, the existence of spatially limited clusters of locally breeding $I$. persulcatus or D. reticulatus in the area cannot be excluded with reasonable certainty, despite the large number of nymphs analysed.

Although there is no evidence for an increased northward distribution of permanent viable populations of $I$. ricinus in Norway [30], studies from Sweden have found I. ricinus to have expanded northwards compared to historical data [6], possibly due to climate change $[9,10]$. Thus, a potential spread of $I$. persulcatus further south in Scandinavia and establishment of $D$. reticulatus within the Scandinavian region could also be expected. Further tick surveillance studies in Scandinavia should acknowledge the possibility of $I$. persulcatus $/ D$. reticulatus becoming established further in this region, and thus the possibility of infections with the Siberian and Far Eastern subtypes of TBEV, B. canis, $R$. raoultii and other pathogens related to these two tick species. It may be advisable to carry out targeted surveillance by flagging at sites with reported cases of B. canis in dogs and Siberian and Far Eastern subtypes of TBE in humans without recent travel histories. Alternatively, it may be recommendable to initiate citizen science projects [31] as local breeding populations of $I$. persulcatus and $D$. reticulatus will be difficult to detect by random surveillance. Our results suggest that $I$. persulcatus and D. reticulatus may not be established in southern Scandinavia.

\footnotetext{
Acknowledgements

We thank Simon Friis-Wandall, Mette Frimodt Hansen, Caroline Greisen, Ana Carolina Cuellar, Najmul Haider, Leif Kristian Sortedal, Philip Thomassen Neset, Preben Ottesen, Alaka Lamsal, Ruchika Shakya, Martin Strnad, Hanne Quarsten, Sølvi Noraas, Åslaug Rudjord Lorentzen, Chiara Bertacco, Kevin Hohwald, Catharina Schmidt, Coco de Koning, and Wenche Okstad for assistance in the field. We would also like to thank the Danish Ministry of the Environment, The Forest and Nature Agency as well as many private landowners for allowing us access to their properties to conduct our sampling.
}

\section{Authors' contributions}

LJK planned and managed the fieldwork set-up, performed fieldwork in Denmark and contributed to field work in Sweden, analysed the data and drafted the manuscript. RB planned the original study, contributed to analysis and drafting the manuscript. AS, KSE, HEHL, KMP, AKA, LK, VK, AS and SS organised and conducted fieldwork in Norway and contributed to drafting the manuscript. PK, MC and MT organised and conducted to fieldwork in Sweden and contributed to drafting the manuscript. AB contributed to analysis and drafting the manuscript. Al and KK performed DNA preparation and the PCR assays and contributed to drafting the manuscript. LMJ contributed to fieldwork, DNA preparation, PCR assays and drafting the manuscript. All authors read and approved the final manuscript.

\section{Funding}

This study was funded by the Interreg V Program (the ScandTick Innovation project, Grant number 20200422), and the Danish Veterinary and Food Administration.

\section{Availability of data and materials}

The datasets analysed during the current study are available from the corresponding author on reasonable request.

Ethics approval and consent to participate Not applicable.

\section{Consent for publication}

Not applicable.

\section{Competing interests}

The authors declare that they have no competing interests.

\section{Author details}

${ }^{1}$ Department of Veterinary and Animal Sciences, Faculty of Health and Medical Sciences, University of Copenhagen, Frederiksberg, Denmark. ${ }^{2}$ Department of Pest Control, Norwegian Institute of Public Health, Oslo, Norway.

${ }^{3}$ Department of Virology, Norwegian Institute of Public Health, Oslo, Norway. ${ }^{4}$ Department of Production Animal Clinical Sciences, Norwegian University of Life Sciences, Oslo, Norway. ${ }^{5}$ Department of Natural Sciences, University of Agder, Kristiansand, Norway. ${ }^{6}$ Sørlandet Hospital Health Enterprise, Research Unit, Kristiansand, Norway. ${ }^{7}$ Department of Production Animal Clinical Sciences, Section of Small Ruminant Research, Norwegian University of Life Sciences, Sandnes, Norway. ${ }^{8}$ Wildlife Ecology Unit, Department of Ecology, Swedish University of Agricultural Sciences, Grimsö, Sweden. ${ }^{9}$ Department of Applied Mathematics and Computer Science, Technical University of Denmark, Lyngby, Denmark. ${ }^{10}$ Department for Diagnostics and Scientific Advice, National Veterinary Institute, Technical University of Denmark, Lyngby, Denmark.

Received: 13 May 2019 Accepted: 3 July 2019

Published online: 09 July 2019

\section{References}

1. Pfäffle M, Littwin N, Muders SV, Petney TN. The ecology of tick-borne diseases. Int J Parasitol. 2013;43:1059-77.

2. Han BA, Yang L. Predicting novel tick vectors of zoonotic disease. In: ICML workshop on \#Data4Good: machine learning in social good applications, New York, NY; 2016. arXiv:1606.06323.

3. de la Fuente J, Estrada-Pena A, Venzal JM, Kocan KM, Sonenshine DE. Overview: ticks as vectors of pathogens that cause disease in humans and animals. Front Biosci. 2008;13:6938-46.

4. Estrada-Peña A, De J, de la Fuente J. The ecology of ticks and epidemiology of tick-borne viral diseases. Antivir Res. 2014;108:104-28.

5. Vu Hai V, Almeras L, Socolovschi C, Raoult D, Parola P, Pagès F, et al. Monitoring human tick-borne disease risk and tick bite exposure in Europe: available tools and promising future methods. Ticks Tick Borne Dis. 2014;5:607-19. 
6. Jaenson TGT, Jaenson DGE, Eisen L, Petersson E, Lindgren E. Changes in the geographical distribution and abundance of the tick /xodes ricinus during the past 30 years in Sweden. Parasit Vectors. 2012;5:8.

7. Jensen PM, Skarphédinsson S, Jensen PM, Kristiansen K. Survey of tickborne infections in Denmark. Emerg Infect Dis. 2005;11:1055-61.

8. Michelet L, Delannoy S, Devillers E, Umhang G, Aspan A, Juremalm M, et al. High-throughput screening of tick-borne pathogens in Europe. Front Cell Infect Microbiol. 2014;4:103.

9. Gage KL, Burkot TR, Eisen RJ, Hayes EB. Climate and vectorborne diseases. Am J Prev Med. 2008:35:436-50.

10. Martens W, Jetten T, Rotmans J, Niessen L. Climate change and vectorborne diseases: a global modelling perspective. Glob Environ Change. 1995:5:195-209.

11. Jaenson TGT, Värv K, Fröjdman I, Jääskeläinen A, Rundgren K, Versteirt $\checkmark$, et al. First evidence of established populations of the taiga tick Ixodes persulcatus (Acari: Ixodidae) in Sweden. Parasit Vectors. 2016;9:377.

12. Bugmyrin SV, Bespyatova LA, Korotkov YS, Burenkova LA, Belova OA, Romanova LI, et al. Distribution of Ixodes ricinus and I. persulcatus ticks in southern Karelia (Russia). Ticks Tick Borne Dis. 2013;4:57-62.

13. Tokarevich NK, Tronin AA, Blinova OV, Buzinov RV, Boltenkov VP, Yurasova $E D$, et al. The impact of climate change on the expansion of /xodes persulcatus habitat and the incidence of tick-borne encephalitis in the north of European Russia. Glob Health Action. 2011;4:8448.

14. Jaaskelainen A, Tikkakoski T, Uzcategui N, Alekseev A, Vaheri A, Vapalahti O. Siberian subtype tickborne encephalitis virus, Finland. Emerg Infect Dis. 2006;12:1568-71

15. Jaaskelainen AE, Sironen T, Murueva GB, Subbotina N, Alekseev AN, Castren J, et al. Tick-borne encephalitis virus in ticks in Finland, Russian Karelia and Buryatia. J Gen Virol. 2010;91:2706-12.

16. Süss J. Tick-borne encephalitis 2010: epidemiology, risk areas, and virus strains in Europe and Asia. An overview. Ticks Tick Borne Dis. 2011;2:2-15.

17. Jääskeläinen A, Tonteri E, Pieninkeroinen I, Sironen T, Voutilainen L, Kuusi $M$, et al. Siberian subtype tick-borne encephalitis virus in /xodes ricinus in a newly emerged focus, Finland. Ticks Tick Borne Dis. 2016;7:216-23.

18. Heyman P, Cochez C, Hofhuis A, van der Giessen J, Sprong H, Porter SR, et al. A clear and present danger: tick-borne diseases in Europe. Expert Rev Anti Infect Ther. 2010;8:33-50.

19. Lindquist L, Vapalahti O. Tick-borne encephalitis. Lancet. 2008;371:1861-71.

20. Földvári G, Široký P, Szekeres S, Majoros G, Sprong H. Dermacentor reticulatus: a vector on the rise. Parasit Vectors. 2016;9:314.
21. Klitgaard K, Chriél M, Isbrand A, Jensen TK, Bødker R. Identification of Dermacentor reticulatus ticks carrying Rickettsia raoultii on migrating jackal, Denmark. Emerg Infect Dis. 2017;23:2072-4.

22. Jongejan F, Ringenier $M$, Putting $M$, Berger $L$, Burgers $S$, Kortekaas $R$, et al. Novel foci of Dermacentor reticulatus ticks infected with Babesia canis and Babesia caballi in the Netherlands and in Belgium. Parasit Vectors. 2015;8:232.

23. Hasle G, Bjune G, Edvardsen E, Jakobsen C, Linnehol B, Røer JE, et al. Transport of ticks by migratory passerine birds to Norway. J Parasitol. 2009;95:1342-51.

24. Øines $\varnothing$, Storli K, Brun-Hansen H. First case of babesiosis caused by Babesia canis canis in a dog from Norway. Vet Parasitol. 2010;171:350-3.

25. Rudander SH. The risk of Dermacentor reticulatus establishing in Sweden (In Swedish, MSc Thesis). Department of Biomedical Sciences and Veterinary Public Health, Swedish University of Agricultural Sciences, Uppsala, Sweden; 2018

26. Bødker R, Petersen RE, Kjær LJ, Isbrand A, Klitgaard K. Do not bring home the meadow tick from your vacation! Dansk Veterinær Tidsskr. 2018;8:42 (In Danish).

27. Solano-Gallego L, Sainz Á, Roura X, Estrada-Peña A, Miró G. A review of canine babesiosis: the European perspective. Parasit Vectors. 2016;9:336.

28. Kjær LJ, Soleng A, Edgar KS, Lindstedt HEH, Paulsen KM, Andreassen ÅK, et al. Predicting and mapping human risk of exposure to Ixodes ricinus nymphs using climatic and environmental data, Denmark, Norway and Sweden, 2016. Eurosurveillance. 2019;24:1800101.

29. Klitgaard K, Højgaard J, Isbrand A, Madsen JJ, Thorup K, Bødker R. Screening for multiple tick-borne pathogens in Ixodes ricinus ticks from birds in Denmark during spring and autumn migration seasons. Ticks Tick Borne Dis. 2019;10:546-52.

30. Soleng A, Edgar KS, Paulsen KM, Pedersen BN, Okbaldet YB, Skjetne IEB, et al. Distribution of Ixodes ricinus ticks and prevalence of tick-borne encephalitis virus among questing ticks in the Arctic Circle region of northern Norway. Ticks Tick Borne Dis. 2018;9:97-103.

31. Laaksonen M, Klemola T, Feuth E, Sormunen JJ, Puisto A, Mäkelä S, et al. Tick-borne pathogens in Finland: comparison of Ixodes ricinus and $I$. persulcatus in sympatric and parapatric areas. Parasit Vectors. 2018;11:556.

\section{Publisher's Note}

Springer Nature remains neutral with regard to jurisdictional claims in published maps and institutional affiliations.
Ready to submit your research? Choose BMC and benefit from:

- fast, convenient online submission

- thorough peer review by experienced researchers in your field

- rapid publication on acceptance

- support for research data, including large and complex data types

- gold Open Access which fosters wider collaboration and increased citations

- maximum visibility for your research: over $100 \mathrm{M}$ website views per year

At BMC, research is always in progress.

Learn more biomedcentral.com/submissions 